\title{
Conducting an immersive community- based assessment of post-hurricane experience among Puerto Ricans: lived experience of medical ecology in an environmental disaster and migration
}

\author{
D. Vega Ocasio* (D, J. G. Pérez Ramos and T. D. V. Dye
}

\begin{abstract}
Background: Two devastating sequential hurricanes impacted Puerto Rico during September of 2017. The hurricanes were traumatic and created social and ecological upheaval throughout Puerto Rico, and subsequently in communities of Central Florida where affected Puerto Ricans migrated. The 2017 hurricane season exposed and exacerbated previous long-standing socio-political, economic, environmental, and health crises, generating a humanitarian emergency in the country. The consequences of these human-ecological disasters destroyed much of Puerto Rico's residential and environmental infrastructure, displacing thousands of people and resulting in an unprecedented migration to the United States. We report on the lived experience of the investigator team and partnership in conducting community-based formative research subsequent to this disaster, research that aimed to identify salient issues relating to the impact of Hurricanes Irma and María on Puerto Rican communities both in Puerto Rico and in Central Florida.
\end{abstract}

Discussion: The challenges faced during the conduct of this research include but are not limited to (1) emotional distress of participants and team members, (2) access to affected populations, and (3) precarious environmental factors, such as unstable infrastructure. To address these challenges, the researchers applied a Critical Medical Ecological paradigm along with qualitative methods to assist constructing explanatory models while obtaining internally-valid (from the community perspective), cathartic narrative accounts of the lived experience of hurricane survivors. The experience of the research team may help inform other investigators conducting applied research during a humanitarian crisis.

(Continued on next page)

* Correspondence: Denisse_vegaocasio@urmc.rochester.edu

Department of Obstetrics and Gynecology, University of Rochester, School of Medicine and Dentistry, 601 Elmwood Avenue, Box 668, Rochester, NY

14642 , USA

(c) The Author(s). 2020 Open Access This article is licensed under a Creative Commons Attribution 4.0 International License, which permits use, sharing, adaptation, distribution and reproduction in any medium or format, as long as you give appropriate credit to the original author(s) and the source, provide a link to the Creative Commons licence, and indicate if changes were made. The images or other third party material in this article are included in the article's Creative Commons licence, unless indicated otherwise in a credit line to the material. If material is not included in the article's Creative Commons licence and your intended use is not permitted by statutory regulation or exceeds the permitted use, you will need to obtain permission directly from the copyright holder. To view a copy of this licence, visit http://creativecommons.org/licenses/by/4.0/ The Creative Commons Public Domain Dedication waiver (http://creativecommons.org/publicdomain/zero/1.0/) applies to the data made available in this article, unless otherwise stated in a credit line to the data. 


\begin{abstract}
(Continued from previous page)
Conclusion: Lessons learned in this research included: (1) usefulness of applying the Critical Medical Ecological model in the development of the project, (2) incorporating participation and methods that prioritize authenticity, (3) understanding the trauma experience and using study methods sensitive to it, and (4) innovating with best approaches to conduct the study given the challenges in post-hurricane Puerto Rico. These lessons could provide new insights on how to conduct in-depth participatory health research with community members who have been traumatized and - often - displaced. This research also demonstrates the value of pre-existing partnerships, critical consciousness in the field team, and medical ecological modeling as experiential for organizing complex, inter-related, multi-level variables that explain community and individual impact of environmental disasters.
\end{abstract}

Keywords: Environment, Disaster, Migration, Hurricane María, Hurricane Irma, Community-based assessment, Medical ecology, Puerto Rico, Qualitative methods, Critical consciousness

\section{Background}

The goal of this reflection is to analyze researchers' experiences working in the context of a humanitarian crisis. We briefly describe the purpose of the study in the selected study site, the methods we employed, and lessons learned from the experience.

\section{Humanitarian context}

During September 2017, Puerto Rico was hit by two devastating, sequential hurricanes (Irma and María). These two natural disasters exposed and exacerbated previous long-standing social-political, economic, environmental, and health crises in the country, generating an extreme humanitarian emergency, disrupting systems, communities, and causing widespread death and destruction [14]. For centuries, Puerto Rico has been exploited and colonized in ways that created vulnerability in its financial security, institutionalized inequitable trade policies, disenfranchised its voting populace, and created unsustainable dependencies $[2,5]$. The lived experience of its citizens in advance of the hurricanes reflected both these vulnerabilities and resilience against adversity in Puerto Rico [6].

Hurricane María is considered to be the worst storm to strike the islands in decades, causing unprecedented damage and affecting the archipelago's 3.4 million inhabitants [7]. The impact of this natural disaster disproportionately affected Puerto Rico's most neglected and marginalized residents - with fewer resources available to help recover and rebuild - many of whom live in more rural and coastal communities and hard-to-reach mountainous areas [8]. The disaster left many communities stranded and without basic necessities including food, water, electricity, and cellphone services [9].

The University of Rochester (UR) has had a longstanding collaborative history with Puerto Rico for the past 20 years, most recently manifested as a collaborative CDC award (The CDC Global and Territorial Health Research Network) [10] that in 2015-2016 pursued community-based fieldwork focused around chronic disease $[11,12]$. With the onset of the Zika outbreak in Puerto Rico in 2016, the University of Puerto Rico (UPR) -UR team rapidly shifted focus to community experiences and participation in Zika-related research [13, 14], culminating in a technology-centered comprehensive pilot project, termed mZAP (móvil Zonas, Acción y Protección) $[14,15]$. With the unexpected occurrence of these two devastating hurricanes in 2017, the joint UPR-UR team abruptly ceased all research activity and transitioned to the creation of a volunteer community assistance strategy (People-to-People for Puerto Rico (\#p2p4PUR)), mobilizing mobile clinic gear and teams in communities where UPR-UR had prior experience and in other communities where assistance was needed $[16,17]$. With recovery in communities underway in 2018, the UPR-UR team resumed and shifted its research focus to document the disaster experience in Puerto Rican communities and among the diaspora community that left the island for the USA.

Natural disasters, such as Hurricane María, can cause significant socio-economic and physical damage to fragile environments and to susceptible populations, effects that can spread beyond the immediate locality [18]. In the case of Puerto Rico, the archipelago was already suffering from a political and economic crisis: the poverty level increased to $44.5 \%$, the infrastructure (including the health care infrastructure) weakened, the economic recession resulted in austerity measures, and the impact from Hurricane Irma two weeks prior to Hurricane María caused a partial collapse of the electrical system $[19,20]$. The island's economic crisis - already impacting many households - fueled a sense of uncertainty and despair among many Puerto Ricans [21]. The 2017 hurricane season destroyed much of Puerto Rico's infrastructure (including residential structures) and shifted natural resources as the landscape experienced visible change [22]. Thousands of properties became uninhabitable with communities upended, leading some residents to relocate within and outside of Puerto Rico [23], while others remained living in fragile dwellings $[5,24,25]$. The complex impact that this disaster had on the overall 
health and disease of the population, survival, and adaptation has yet to be fully documented [23, 26-29].

The purpose of this paper is to describe the lived experience of the investigators who conducted this work, presented as a case study, to draw recommendations for other researchers who may need to conduct research in times of humanitarian disaster.

\section{Lesson 1: using the critical medical ecological model helped} organize our work and response

Working amidst the devastation of the hurricanes, an appropriate framework needed to be implemented to capture the complex human-ecological calamity that resulted from the mentioned natural disasters. The Critical Medical Ecological paradigm [22, 30] provided a useful heuristic device to examine human interactions with their environment, comprehensively defined to include physical, social, political, and biological elements [3133]. This analytical framework prioritizes multidimensional social (including economic, demographic, and cultural) relationships and biological aspects of community members while acknowledging the interdependent role of bioenvironmental factors and their associations with disease [34]. The model helped us prepare the research questions and fieldwork through thinking about how humans are influenced by multi-level ecosystems of which they are part: including the macro-micro ecosystems, the abiotic (e.g., floods) and biotic components (e.g., immune system responses, stress hormones), and multiple levels of human organization. In this project, the Critical Medical Ecological framework additionally drove both the aid/relief response [17] and subsequent research with Puerto Ricans and the diaspora, with the team immersing in the midst of post-hurricane communities to gather, first-hand, qualitative experiences from community members. The study aimed to provide a comprehensive approach to better understand the amalgam of factors that impacted Puerto Ricans through the post-hurricane experience, including their decisions - if made - to depart the islands.

\section{Lesson 2: incorporation of participation and methods that prioritize authenticity}

Investigators recognized the need to approach our research participants as collaborators and to strive toward building and relying upon authentic partnerships to collect and analyze data. We sought to build a grounded, community-based ecological model of coping and response to surviving Hurricanes Irma and María, including identifying determinants of and responses to migration from Puerto Rico to the continental USA. From our previous aid relief efforts in Puerto Rico with \#p2p4PUR, we understood that qualitative methods were required to capture the range and nuance of the "lived experience" subsequently expressed by community members. Qualitative methods present the opportunity to capture natural, insider perspectives which - oftentimes - prove cathartic for participants [35-37].

To achieve community authenticity in our approach (methodologically, to improve validity), the qualitative interview guide was shaped by the Critical Medical Ecology paradigm and was, in part, based on the team's prior experience in conducting qualitative work in Puerto Rico around Zika [13]. The interview guide was organized sequentially to walk the participants through their experience from pre- to post-hurricane, with partially structured questions that were focused yet allowed for elaboration, explanation, and interpretation through the interview's conversation. Additional questions/ themes were included based on informal conversations around priorities with project partners. The final themes covered included participants' peri-hurricane experiences, the social-ecological damage, health impact, reactions, and migration decisionmaking.

The project was reviewed and approved by 12 community groups, agencies, and organizations in Puerto Rico and Orlando. Prior to conducting the research, participants received an information sheet, and provided verbal consent for audio-recording. Field notes were taken by interviewers during and immediately after each interview to facilitate a more comprehensive analysis process. Moreover, a professional transcription firm was contracted to transcribe audio recordings to text, which were subsequently reviewed and edited by native Spanish speakers on the team. Importantly, to maintain research fidelity and validity, all research material was maintained, collected, and analyzed in Spanish by an exclusively bilingual Latinx, Spanish-fluent team. Study communities were selected from areas familiar to the team through previous research collaboration (that occurred prior to the hurricanes), and in communities the team became familiar with through its relief work (\#p2p4PUR).

The study data was collected from 97 Puerto Rican participants (65 female and 32 male). In Puerto Rico, the study was conducted in nine municipalities around the archipelago encompassing different ecological zones (mountainous, metropolitan, rural, and outer island) to capture a range of ecological exposures for a total of 23 interview instances (17 focus groups and 6 individual interviews) among community members. In Florida, the study was conducted in Orlando (a major resettlement hub for post-hurricane Puerto Ricans) with a total of 27 participants (21 females and 6 males) in four focus groups. The Orlando groups covered the same topics as the Puerto Rico-based groups, but additionally focused on the post-hurricane Puerto Rican diaspora that migrated to the USA and their challenges associated with relocation. 
Analysis prioritized community voices through iterative thematic analysis [38] and note-taking facilitated a preliminary understanding of salient community issues. Transcripts were uploaded to Dedoose (Socio-Cultural Research Consultants, Manhattan Beach, CA, v.8.3), a web-based qualitative data analytical software, which helped researchers synthesize multiple levels of qualitative data into a single platform, and enabled multi-layered and meaningful analysis [39]. The team iteratively developed a codebook that captured both the emic (community perspective) experience and also selective etic (research perspective from outside the culture) analytic codes required for analysis. A rigorous and extensive coding verification process by two native Spanish speaking team members was established, which included debriefing and peer validation of coding. The final coding process was completed by four native Spanish-speaking team members using the transcribed interviews.

\section{Lesson 3: understand the trauma experience and incorporate study methods sensitive to it}

Given the massive trauma experienced by Puerto Ricans in this period, and our witness to that suffering, we needed to prioritize understanding such experiences and incorporate it into our approach. This research study was able to observe and describe the complexity of the pre- and posthurricane situation impacting Puerto Ricans. The results showed (summarized in Table 1) that the precarious conditions that followed Hurricane María were the result of a failed complex system that covers every layer of the Critical Medical Ecological model (sociocultural, biological, healthcare and abiotic): geographical areas, governmental response, financial limitations, individual decisions, inequitable social relationships, and a foreseen failure of the healthcare system. As explained in the model, Hurricane María had an effect from the community level to the individual level, for example complete communities were destroyed by the forces of the wind and many residents were affected, individually, by those repercussions. In many cases, the post-hurricane conditions increased or exacerbated social determinants of health that led to complicated health outcomes (increased comorbidities associated with pre-existing health conditions, restricted access to food and water, and death). Indeed, presenting "death narratives" was one of the most common themes in our project:

"Sí, luego del huracán, llegó, llegó mucha depresión en muchas personas, muchas historias que se escuchan porque mientras uno hace fila, uno conoce gente, y uno escucha tanta historia, que yo creo que la depresión de muchas personas de haber perdido todo fue uno de los mayores problemas, y a base de la depresión viene el suicidio, y

Table 1 Critical Medical Ecological Model: Identifying the broader factors that led to the precarious conditions before, during, and after the hurricane's impact

\begin{tabular}{|c|c|c|c|c|}
\hline & Sociocultural & Biological & Health Care & Abiotic \\
\hline Community & $\begin{array}{l}\text { Systems collapse (Water, electricity, } \\
\text { food) } \\
\text { Disbalanced social and political } \\
\text { relationships } \\
\text { Unemployment } \\
\text { Poverty } \\
\text { Limited access to and poor } \\
\text { distribution of financial resources } \\
\text { Precarious infrastructure } \\
\text { Late federal/state response } \\
\text { External dependency }\end{array}$ & $\begin{array}{l}\text { Infectious disease exposure } \\
\text { (e.g. leptospirosis) } \\
\text { Shifting breeding grounds } \\
\text { for vectors } \\
\text { Bacterial, flora, fauna change }\end{array}$ & $\begin{array}{l}\text { Collapse of medical facilities } \\
\text { Limited health care personnel } \\
\text { Only one trauma center in the } \\
\text { island } \\
\text { Limited medicines available } \\
\text { Poor surveillance } \\
\text { Traumatized health workers }\end{array}$ & $\begin{array}{l}\text { Mountains } \\
\text { Wind } \\
\text { Rain } \\
\text { Flood } \\
\text { Debris } \\
\text { Temperatures and humidity } \\
\text { Mudslides } \\
\text { Elevation } \\
\text { Poor roads and bridges }\end{array}$ \\
\hline Household & $\begin{array}{l}\text { No communication } \\
\text { Weak building construction } \\
\text { Lack of home ownership } \\
\text { documentation } \\
\text { Family income } \\
\text { Gender roles } \\
\text { Migration/relocation } \\
\text { Poor access to available aid and } \\
\text { resources } \\
\text { Social and family networks disrupted }\end{array}$ & $\begin{array}{l}\text { Exposure to Infectious } \\
\text { Diseases } \\
\text { Stress/Trauma } \\
\text { Impact of trauma in chronic } \\
\text { diseases } \\
\text { Increases in household risk } \\
\text { Increase in vector and } \\
\text { vermin exposures } \\
\text { Crop loss/ loss of food } \\
\text { sources }\end{array}$ & $\begin{array}{l}\text { Isolation (unable to access } \\
\text { medical facilities) } \\
\text { Limited assistance for } \\
\text { bedridden family members } \\
\text { No reliable access to } \\
\text { medication and treatment } \\
\text { New, important social } \\
\text { determinants emerge }\end{array}$ & $\begin{array}{l}\text { Housing Damage } \\
\text { Loss of material goods, } \\
\text { appliances, and equipment }\end{array}$ \\
\hline Individual & $\begin{array}{l}\text { Unemployment } \\
\text { Denial about hurricane } \\
\text { Isolation } \\
\text { Loneliness, isolation, depression, and } \\
\text { anxiety } \\
\text { Loss of social and family relationships } \\
\text { Loss of role identification }\end{array}$ & $\begin{array}{l}\text { Pre-existing medical } \\
\text { conditions } \\
\text { Weaken immune system } \\
\text { Stress response } \\
\text { Injuries }\end{array}$ & $\begin{array}{l}\text { Unable to access healthcare } \\
\text { facilities or treatments } \\
\text { Stigma related to mental } \\
\text { health care } \\
\text { Loss of medication and } \\
\text { therapeutic interventions }\end{array}$ & $\begin{array}{l}\text { Lack of Protective clothing/ } \\
\text { footwear } \\
\text { Sleeping environment } \\
\text { disturbed }\end{array}$ \\
\hline
\end{tabular}


se escucharon muchos casos en Puerto Rico de personas no solo que se enfermaron, también optaron, tomaron la decisión de suicidarse ..." ("Yes, after the hurricane, there was a lot of depression in many people, you hear many stories while waiting on lines, you meet people, and you hear so many stories, that I believe that the depression of many people resulted by having lost everything, it was one of the bigger problems, and with depression comes suicide, and many cases were heard in Puerto Rico of people not only who got sick, they also chose, they took the decision to commit suicide ..."

- Female participant in rural focus group

The complexity of these societal challenges, and how they made an impact at an individual level, resulted in the displacement and migration of many Puerto Ricans to the continental United States. Factors mentioned influencing this decision include: (1) unemployment as a result of the hurricane, (2) loss of household materials, and (3) medical needs such as dialysis and cancer treatment. The Critical Medical Ecological model allowed us to identify broader contexts of the situations that led to such precarious conditions before, during, and after the hurricane's impact. The model permitted us to organize and to understand how previous social-environmental challenges influenced the fragile conditions in the aftermath - such as the long-standing humanitarian-financial crises that restricted families' abilities to purchase goods, or the perceived confidence in community members due to a lack of recent experience with hurricanes.

Hurricane Irma and especially Hurricane María, presented traumatic events that subsequently created social and ecological upheaval throughout Puerto Rico, and in the diaspora communities of Central Florida (and elsewhere) where Puerto Ricans migrated. The consequential effects of this event and the challenges that followed were multifactorial, complex, and reflected interdependent social and health problems in an ecologically destructive context. Hence, the medical ecological paradigm and qualitative methods helped constructively build explanatory models while obtaining emic (and somewhat therapeutic) narrative accounts of the lived experience of hurricane survivors.

\section{Emotional distress of participants}

Many participants did not have the opportunity to talk about their experiences previously, creating both challenges for the team (emotional sensitivity to the suffering of others) and research needs (to elicit first-hand accounts of a disastrous event from those who experienced it). Occasionally, the traumatic events that individuals experienced led to feelings of despair, sadness, and anxiety among participants. Prior to conducting field work, the team contacted local mental health institutions and organizations in each of the respective towns to identify referral information if needed during the interview process. All participants received a pamphlet that included the contact information for mental health assistance, and an island-wide helpline. Organizing partners who hosted data collection instances were bestsuited to refer participants to local resources before, during, and after the period of this study.

\section{Emotional sensitivity of team members}

The team encountered the stories of the struggles that participants experienced; their survival narratives and the effect these had both physically and mentally in the participants' lives challenged the team's capacity to remain both objective and empathetic in conducting this research. All three co-PIs of this study had relatives impacted in Puerto Rico from the hurricanes - this event was a personal tragedy for all involved, yet an important, action-driven scientific opportunity to potentially learn local strategies that could reduce the damaging impact of future natural disasters.

\section{"Esta es la primera vez que alguien nos pregunta como fue nuestra experiencia con el huracán." ("This is the first time someone ask us about how our experience with the hurricane was.") \\ Male participant, Rural Area, Focus Group}

The daily debriefing sessions among team members not only served to discuss major learnings, but it also served as an informal therapeutic session to discuss well-being and mental health needs, as required.

Lesson 4: we innovated best approaches to create and conduct this study given the physical, social, and technical challenges in post-hurricane Puerto Rico

We had to develop innovative methods of data collection, such as leveraging pre-existing community networks from our other work in Puerto Rico, relying upon social media to access communications, and logistical planning sensitive to roads, weather, and timing.The ecological damage in the aftermath of the hurricanes presented logistical difficulties in reaching susceptible communities due to unstable infrastructure, such as poor road conditions, lack of electricity, and minimal communication. As part of the recruitment challenges because of the limited communication infrastructures damaged by Hurricane María - the research group used different strategies to communicate with community partners, in particular social media networks such as WhatsApp and Facebook. The research team divided the island into quadrants to facilitate logistics and to ensure 
geographic coverage, prioritizing the communities that received humanitarian help previously from the research team.

Power outages and cellphone disruptions occurred due to the unstable infrastructure post-hurricane while completing the interview process. Road conditions made traditional routes inaccessible and continuing rain caused the team to monitor flood levels in their route. The research team worked together with community members to conduct interviews during times when it was more convenient to the community (typically during daylight and outside). Further, logistics for interview events were also developed in collaboration with community leaders beforehand, including mapping routes and locations (e.g., town hall, town bakery).

The challenges presented showcase the significant environmental and social risks that can follow natural disasters and emergency situations. Such natural hazards are likely to trigger additional challenges for both the researchers and the participants, perhaps limiting their ability to access certain communities, or limiting ability of potential participants to reach the meeting place. Recognizing the scale of disaster, and the impact it had on the population at a physical and psychological level is important for ensuring an effective response, insights informed by the team's humanitarian efforts that preceded this research.

\section{Community partnership}

This project was built on those community partnerships where the team has developed visibility and trust, either arising from the pre-hurricane research projects with communities throughout the island, or through subsequent experience with new communities through the \#p2p4PUR relief response. Research partnerships in Orlando, however, did not pre-exist the hurricanes. As this research project emerged, the UR team networked to reach city officials and non-profit organizations focused on assisting Puerto Ricans settling in Orlando and community groups serving and advocating for various needs of the resettled Puerto Rican population. The team's prior work in Puerto Rico added to their credibility to undertake this work and provided an opportunity for close collaboration with diaspora leaders.

The selection of the research team for this work (and for the collaborative research that preceded the hurricanes) was deliberate and crucial, improving validity and potential for action by prioritizing critical consciousness (Paulo Freire's concept of conscientização [40]), collecting and analyzing participants "lived experience" through a research team with strong connection to Puerto Rico, its history, culture, practices, and its contemporary social-political situation.

\section{Scientific contribution}

Puerto Rico's history has resulted in multiple forms of social determinants of health that created social inequalities including lack of political representation (primarily in the USA), unfair workforce practices, institutionalized social control, racism, corruption, gender-based violence, poverty, and health discrimination [5, 41]. Given the ongoing austerity measures imposed on the country, the dual impact of the 2017 hurricanes have had an especially harsh impact on Puerto Rican communities [41]. The devastating, cumulative consequences of the hurricanes resulted in both an ecological and a multi-level social shift within the individual, household, and community levels that collapsed the medical infrastructure, exacerbated chronic diseases, increased infectious diseases, impacted mental health rapidly in community members, and created a significant migration to the continental United States [5]. Nonetheless, the damaging effects of these hurricanes are also a result of previous socio-economic and political challenges affecting the island.

Typically, natural disasters result in significant loss and damage leading most scientific research studies to focus on the health outcomes and risk factors that are presented in the wake of such an event. Such studies, however, subsequently often fail to evaluate the previous conditions and behaviors that may contribute to these post-disaster impacts. Understanding the social-ecological landscape before the natural disaster, however, provides a deeper understanding of the level of vulnerabilities and strengths in communities, and the complexities of how individuals perceive and respond to risks. The complex situation in Puerto Rico - together with the unprecedented damage caused by this natural disaster - made visible the need to evaluate and analyze the contributing roles of the physical and social-environmental circumstances of families, and the underlying factors contributing to the rapid collapse in living conditions in the aftermath of the hurricane. Consequently, this study sought to explore and answer questions concerning the type of services required to meet community needs, actions necessary to make programs or services more effective, and strategies required to overcome newly-defined problems, all from a community-centered perspective. This perspective is intended to assist stakeholders in developing future policies and plans aimed at addressing risk factors that contribute to a community's susceptibilities in a natural disaster. This type of research is essential to offer policy-makers specific evidence grounded in the experiences of those most likely impacted by policy decisions (e.g., community members), taking into account related cultural, social, political, and economic realities [42]. Furthermore, the results from this field work are expected to assist community leaders in the understanding of the risk factors associated with natural disasters (specific to their community), community-driven 
methods of organization, and how community engagement is an integral part of response from the onset of the emergency. The research team intends to continue collaboration with participant leaders and to report back the results of this work.

\section{Conclusion}

This case study sought to describe salient issues and factors relating to conducting research on the impact of Hurricanes Irma and María in Puerto Rican communities - both in Puerto Rico and Central Florida - on how ecological risks may have changed, their impacts on health, and the responses and determinants for relocation. Crucial among the lessons learned are that researchers needed to be sensitive to, and ready for, recollecting negative, emotional events, and to allow the team (scientifically) to express that emotion. The data collected during this research will serve future studies as best practices for community-engagement and to address data collection rapidly, post-disaster. The importance of collecting and disseminating this research allows scientific teams to learn about the intricacies and challenges associated with a natural disaster within a complex medical ecological theoretical framework and to potentially prepare prevention and remediation mechanisms for future events.

In addition, researchers need to become acquainted with the risks and benefits for such types of methods (for example, the lengthy time required to properly code qualitative data and analyze with validity) and the issues of importance prior to engaging communities, understanding the potential harms for each specific setting, and preparing to manage possibly daunting situations. Seeing the community as true partners in collectively documenting and voicing their experiences helps leverage the strengths of the methods and creates a mutuallysupportive research environment. Although communities were not expected to have a direct benefit from these experiences as our preliminary findings suggest, community participants describe the therapeutic effects of being allowed to talk about their experiences. As previous research has demonstrated, the importance of a social support system after a traumatic event helps cope with the distress occurring during the emergency [32]. Engaging with respective stakeholders and community leaders prior to the start of and after the study is vital for success.

Because of our commitment to Freirean community principles of conscientização, equity, and respect, this research study provided an environment of respect and trust, where community members' voices were heard and prioritized. Additionally, having collaborated previously with stakeholders and community members facilitated the process of respect and trust. The team was predominantly Puerto Rican - all with prior experience in Puerto Rico - collecting and analyzing data in local parlance without hierarchical power dynamics guiding our team's actions. This deliberate lack of a hierarchical structure ensured that participants and researchers coexisted in an environment of cultural respect and understanding. This respect represented an significant lesson among the researchers because it provided a deeper understanding of the importance in creating meaningful connections with participants beyond the research needs and - in this example - before the disaster even occurred. Finally, reporting results back to the community in a timely manner, obtaining feedback, and refining conclusions, is a critical component of this process that helps bring closure to this phase of the work.

\section{Abbreviations \\ CDC: Center for Disease Control and Prevention; UPR: University of Puerto Rico; UR: University of Rochester; mZAP: Zonas, Acción y Protección; \#p2p4PUR: People-to-People for Puerto Rico; RQI: Rapid Qualitative Inquiry}

\section{Acknowledgements}

We are grateful for the engagement of our community partners and project participants. Further we extend our appreciation to Camila Ospina Fadul and Ivelisse Rivera for their contributions to the design and implementation of this project and to Jishyra Serrano, Desarey Morales, Lisette Alcantara, and Zahira Quiñones Tavarez for their contributions in the analysis process.

\section{Authors' contributions}

Each author substantially contributed to this research study, including design, data collection, and analysis. All authors were involved in the development of the interview guide and planning process to be used in the field. Individually, TDVD, as the senior member of the team was involved in the process of IRB approvals, design of the work, analysis, and guiding each step of the research study. JGPR, organized and kept in contact with all groups involved in Puerto Rico and Central Florida. Additionally, he was involved in the process of data collection in the field and analysis of data. DVO, was involved in the planning process (logistics), data collection in Puerto Rico, analysis of results and organization of the analysis process. Each author has approved the submitted version and has agreed both to be personally accountable for the author's own contributions and to ensure that questions related to the accuracy or integrity of any part of the work, even ones in which the author was not personally involved, are appropriately investigated.

\section{Funding}

This work was funded by Cooperative Agreement Number 1U48DP00502601S1, funded by the Centers for Disease Control and Prevention, Prevention Research Centers Program. The contents of the presentation are the responsibility of the authors and do not necessarily represent the official views of the Centers for Disease Control and Prevention or the Department of Health and Human Services. Denisse Vega-Ocasio received support from the Translational Biomedical Science PhD program at the University of Rochester (\# TL1TR002000 from the National Center For Advancing Translational Sciences, National Institutes of Health) and \#BWF1014095 from the Burroughs Wellcome Fund.

\section{Availability of data and materials}

No data is available since the paper is on our experience and as qualitative data for the main study is identifying, we will not make it publicly available.

\section{Ethics approval and consent to participate}

The study was reviewed and approved by the University of Rochester 's Research Subjects Review Board as an expedited study (RSRB00071756). We further confirm that any aspect of the work covered in this manuscript that has involved human participation has been conducted with the ethical 
approval of all relevant bodies and that such approvals are acknowledged within the manuscript.

\section{Consent for publication}

Not applicable.

\section{Competing interests}

We wish to confirm that there are no known conflicts of interest associated with this publication and there has been no significant financial support for this work that could have influenced its outcome.

Received: 15 May 2020 Accepted: 20 October 2020

Published online: 29 October 2020

\section{References}

1. Zorrilla CD. The view from Puerto Rico-hurricane Maria and its aftermath. N Engl J Med. 2017;377(19):1801-3.

2. Rodríguez-Díaz CE. Maria in Puerto Rico: natural disaster in a colonial archipelago. Am Pub Health Assoc. 2018;108:30-32.

3. Zolnikov TR. A humanitarian crisis: lessons learned from hurricane Irma. Am Pub Health Assoc. 2018;108:27-8.

4. Santos-Lozada AR, Howard JT. Use of death counts from vital statistics to calculate excess deaths in Puerto Rico following hurricane Maria. Jama. 2018;320(14):1491-3.

5. Benach J, Díaz MR, Muñoz NJ, Martínez-Herrera E, Pericàs JM. What the Puerto Rican hurricanes make visible: chronicle of a public health disaster foretold. Soc Sci Med. 2019;238:112367.

6. Pérez-Ramos JG, Mclntosh S, Barrett ES, Vélez-Vega CM, Dye TD. Qualitative assessment of environmental health risk perceptions and community challenges in a Puerto Rican community: change and continuity in response to hurricanes Irma and María. Behav Med. 2019;46:3-4, 231-244. https://doi.org/10.1080/08964289.2019.1700894.

7. Pasch R, Penny A, Berg R. Tropical cyclone report hurricane Maria (AL152017). Miami: National Hurricane Center; 2018.

8. Alcorn T. Puerto Rico's health system after hurricane Maria. Lancet. 2017; 390(10103):e24.

9. Kishore N, Marqués D, Mahmud A, et al. Mortality in Puerto Rico after hurricane maria. N Engl J Med. 2018:379(2):162-70.

10. De Ver DT, Fogg $T$, Demment $M$, et al. Leveraging CTSA informatics capacity to expand global health engagement and research capacity in Latin America and the Pacific. J Clin Transl Sci. 2017;1(S1):19.

11. Vega CV, Murphy C, Figueroa A, Dye TDV, Pérez-Ramos J, Mclntosh S. Knowledge, opinions, and experiences concerning clinical and genetic testing: voices of research participants in Puerto Rico. Ann Glob Health. 2016;82:566

12. Dye T, Velez Vega C, Pérez Ramos J, Cardona Cordero N, Vega Ocasio D, McIntosh S. An opportunity to restore scientific justice? Willingness to participate in genetic research in two rural Puerto Rican communities. American Society of Human Genetics Annual Meeting October 2019, Houston, Texas 2019.

13. Vega CV, Murphy C, Pérez-Ramos J, Dye TDV. Eso viene de por ahí'Community Perception of Zika and Mosquito-borne Virus in Puerto Rico. Ann Glob Health. 2017:83:158.

14. Perez-Ramos JG, Mclntosh S, Vega CMV, Barrett ES, De Ver Dye T. mZAP (Zonas, Accion y Proteccion): empowering communities with mobile strategies for mosquito-borne disease control in tropical environments. J Clin Transl Sci. 2017;1(S1):41.

15. Pérez-Ramos J, Vélez-Vega C, Torres-Zayas H, Mclntosh S, Barrett E, Dye T. "Culebra es una isla olvidada:"Environmental Risk Perceptions and Challenges on a Small Outer Island of Puerto Rico. 9th Annual Consortium of Universities on Global Health (CUGH) Global Health Conference 2018, March 16-18, New York City, NY, USA. 2018.

16. Perez-Ramos JG, Zayas HT, Cordero NRC, et al. 2231 research partnership, community commitment, and the people-to-people for Puerto Rico (\# p2p4PUR) movement: researchers and citizens in solidarity. J Clin Transl Sci. 2018;2(S1):74.

17. Pérez Ramos J, Dye T. An ecological perspective on the humanitarian role of academia after natural disasters: \#p2p4PUR, a preventive and emergency preparedness approach in post-hurricane Puerto Rico. San Diego: American Public Health Association Annual Meeting; 2018. 2018.
18. Loayza NV, Olaberria E, Rigolini J, Christiaensen L. Natural disasters and growth: going beyond the averages. World Dev. 2012;40(7):1317-36.

19. National Low Income Housing Coalition. Deep Poverty Complicates Recovery Efforts for Puerto Rico. https://nlihc.org/resource/deep-povertycomplicates-recovery-efforts-puerto-rico. Published April 2019. Accessed.

20. Semega JL, Fontenot KR, Kollar MA. U.S. Census Bureau, Current Population Reports, P60-259, Income and Poverty in the United States: 2016. Washington, DC: U.S. Government Printing Office; 2017.

21. Lugo AE. Social-ecological-technological effects of hurricane María on Puerto Rico: planning for resilience under extreme events. Cham: Springer; 2018.

22. Dye T. in. Sobre las conciencias de los hombres: A medical ecological view on post-Maria Puerto Rico (Part 1-4). Vol August 26 2019: SpringerOpen; 2017. http://blogs.springeropen.com/springeropen/author/timdye/. Accessed July 2020

23. Meléndez E, Hinojosa J. Estimates of post-hurricane Maria exodus from Puerto Rico. Center for Puerto Rican Studies, Hunter College CUNY, NY, NY, Research Brief RB2017-01. https://centropr.hunter.cuny.edu/research/datacenter/research-briefs/estimates-post-hurricane-maria-exodus-puerto-rico.

24. Shermeyer J. Assessment of electrical and infrastructure recovery in Puerto Rico following hurricane Maria using a multisource time series of satellite imagery. Paper presented at: Earth Resources and Environmental Remote Sensing/GIS Applications IX2018.

25. Hinojosa J, Román N, Meléndez E. Puerto Rican post-Maria relocation by states. Center Puerto Rican Stud. 2018;1(1):1-15.

26. Scaramutti C, Salas-Wright CP, Vos SR, Schwartz SJ. The mental health impact of hurricane Maria on Puerto Ricans in Puerto Rico and Florida. Disaster Med Public Health Prep. 2019;13(1):24-7.

27. Barrera R, Felix G, Acevedo $V$, et al. Impacts of hurricanes Irma and Maria on Aedes aegypti populations, aquatic habitats, and mosquito infections with dengue, Chikungunya, and Zika viruses in Puerto Rico. Am J Trop Med Hygiene. 2019;100(6):1413-20.

28. Ferré IM, Negrón S, Shultz JM, Schwartz SJ, Kossin JP, Pantin H. Hurricane Maria's impact on Punta Santiago, Puerto Rico: community needs and mental health assessment six months Postimpact. Disaster Med Public Health Prep. 2019;13(1):18-23.

29. Hu T, Smith R. The impact of hurricane Maria on the vegetation of Dominica and Puerto Rico using multispectral remote sensing. Remote Sens. 2018;10(6):827.

30. De Ver DT, Muir E, Farovitch L, Siddiqi S, Sharma S. Critical medical ecology and SARS-COV-2 in the urban environment: a pragmatic, dynamic approach to explaining and planning for research and practice. Infect Dis Poverty. 2020;9(1):1-7.

31. McElroy A, Townsend P. Medical anthropology in ecological perspective. In. Boulder: Westview Press; 2015.

32. Dubos R. So human an animal: how we are shaped by surroundings and events. New York: Scribner; 1968

33. Dye TD, Sy A, Albert $P$, et al. Critical medical ecological perspectives on diabetes in the Pacific Islands: colonialism, power, and balance in humanenvironment interaction over time. Lancet Glob Health. 2018;6:S36.

34. Chin NP, Dye TD. The health and wealth of mountain communities. Matern Child Health J. 2016;20(12):2413-4.

35. Dempsey L, Dowling M, Larkin P, Murphy K. Sensitive interviewing in qualitative research. Res Nurs Health. 2016;39(6):480-90.

36. Wolgemuth JR, Erdil-Moody Z, Opsal T, et al. Participants' experiences of the qualitative interview: considering the importance of research paradigms. Qual Res. 2015;15(3):351-72.

37. Bourne $A H$, Robson MA. Participants' reflections on being interviewed about risk and sexual behaviour: implications for collection of qualitative data on sensitive topics. Int J Soc Res Methodol. 2015:18(1):105-16.

38. Beebe J. Rapid qualitative inquiry: a field guide to team-based assessment. Walnut Creek: Rowman \& Littlefield Publishers; Altamira Press; 2014.

39. Sociocultural Research Consultants. Dedoose 7.0. 23, web application for managing, analyzing, and presenting qualitative and mixed method research data. Los Angeles: SocioCultural Research Consultants; 2016. 2018.

40. Freire P. Pedagogy of the Oppressed (London, Sheed and Ward). Translated by Myra Bergman Ramos. Originally published, New York, Herder and Herder, 1970.

41. Brown P, Vega CMV, Murphy CB, et al. Hurricanes and the environmental Justice Island: Irma and Maria in Puerto Rico. Environ Justice. 2018;11(4):148-53.

42. Walker R. Applied qualitative research. Brookfield: Gower Pub Co; 1985.

\section{Publisher's Note}

Springer Nature remains neutral with regard to jurisdictional claims in published maps and institutional affiliations. 